\title{
Kajian Biblika Tentang Makna Roti dan Anggur dalam Perjamuan Kudus Berdasarkan Matius 26:26-29 dan Implikasinya Terhadap Pengajaran Perjamuan Kudus dalam Gereja
}

\author{
Gustian Limbuk \\ Sekolah Tinggi Filsafat Theologia Jaffray Makassar
}

\begin{abstract}
Abstrak
Tujuan penelitian yang dilakukan oleh penulis dalam skripsi ini adalah untuk mengetahui makna roti dan anggur dalam Perjamuan Kudus berdasarkan Matius 26:26-29, serta apa implikasinya terhadap pengajaran Perjamuan Kudus dalam Gereja. Dalam penelitian ini penulis menggunakan metode kualitatif, yaitu metode penelitian literatur/kepustakaan (Library Research), terhadap berbagai sumber diantaranya: Alkitab, buku-buku tafsiran yang membahas tentang roti dan anggur dalam Perjamuan Kudus dan juga ditunjang dengan bantuan media elektronik. Berdasarkan tujuan dan metode yang digunakan penulis di atas, maka hasil dari penelitian ini adalah sebagai berikut: Pertama, roti dalam Perjamuan Kudus dimaknai sebagai lambang dari tubuh Yesus. Kedua, anggur dalam Perjamuan Kudus dimaknai sebagai lambang dari darah Yesus.
\end{abstract}

Kata - kata Kunci: Anggur, Perjamuan Kudus, Roti.

\section{Pendahuluan}

\section{Latar Belakang Masalah}

Sejak dahulu Perjamuan Kudus sudah menjadi persoalan di dalam gereja, bahkan persoalan ini masih berlaku hingga saat ini. Surat 1 Korintus 11:23-25 menceritakan Perjamuan Kudus yang diajarkan oleh Rasul Paulus kepada orang -orang yang ada di Korintus pada waktu itu. Firman Tuhan di atas mengacu kepada Perjamuan Kudus yang diadakan oleh Tuhan Yesus menjelang hari kematian-Nya, yang juga diceritakan dalam Injil Sinoptik yakni di dalam Injil Matius 26:26-29, Injil Markus 14:22-15, dan Injil Lukas 22:1520. Ketika Tuhan Yesus menetapkan Perjamuan Kudus Ia mengatakan: "Ambillah, makanlah, inilah tubuh-Ku" (Matius 26:26) dan "minumlah, kamu semua, dari cawan ini. Sebab inilah darah-Ku, darah perjanjian, yang ditumpahkan bagi banyak orang untuk pengampunan dosa" (Matius 26:27-28). Kehadiran Kristus dalam Perjamuan Kudus sangat sering dipersoalkan baik antara golongan Katolik Roma dan Protestan maupun di dalam Protestantisme sendiri, yakni antara kaum Reformed dan Lutheran. ${ }^{1}$

Menurut pandangan Reformed dan Lutheran, Theol. Dieter Becker menuliskan:

\footnotetext{
${ }^{1}$ Theol. Dieter Becker, Pedoman Dogmatika, Suatu Kompendium Singkat (Jakarta: BPK. Gunung Mulia, 1991), 160.
} 
Teolog Reformed dan Lutheran, memberikan perdebatan lama antara kehadiran Kristus secara real dalam Perjamuan Kudus baik secara spiritual yang mengarah kepada kehadiran-Nya secara personal. Dalam dalil-dalil Arnoldshain (Jerman) menekankan bahwa Yesus hadir dalam Perjamuan Kudus tetapi kurang menekankan cara bagaimana Ia hadir. ${ }^{2}$

Sedangkan menurut pandangan gereja Reformed yang mengatakan bahwa Yesus hadir dalam Perjamuan Kudus, tetapi tidak secara fisik atau tubuh-Nya, tetapi kehadiranNya dalam Perjamuan Kudus berada di dalam sakramen tersebut yaitu dengan cara rohani atau dinamis. ${ }^{3}$ Berbeda lagi dengan pandangan gereja Lutheran yang menganut prinsip Consubtansiasi. Pandangan ini mengatakan bahwa roti dan anggur tidak berubah menjadi tubuh dan darah Yesus dan menolak ide pengorbanan ulang dan ide tentang Saserdotalisme. ${ }^{4}$

Ulrich Zwingli memberikan pendapatnya yang definitif mengenai Perjamuan Kudus, ia mengutarakan pendapatnya:

Pendapatnya didasarkan atas pendapat Cornelis Hoen (seorang ahli Belanda), yang disampaikannya melalui surat. Ulrich Zwingli memahami perkataan Yesus "Inilah tubuh-Ku" sebagai "Ini menandai tubuh-Ku." Bagi dia tidak ada hubungan yang jelas antara tanda dan apa yang ditandai. Menurutnya Allah adalah roh, dan roh hanya dapat berkata kepada roh. Sama seperti pikiran humanis pada waktu renaissance, demikian pula pikiran Ulrich Zwingli dikuasai oleh pertentangan yang berbeda antara materi dan roh. ${ }^{5}$ Kudus:

Ulrich Zwingli memberikan pandangannya yang lebih jelas mengenai Perjamuan

Ia mengatakan bahwa roti dan anggur dalam Perjamuan Kudus hanya sebagai peringatan saja. Hanya merupakan simbol dari tubuh dan darah Yesus. Dari pernyataannya ini ia sebenarnya mengakui "praesentiarealis" atau Yesus sungguhsungguh hadir di dalam Perjamuan Kudus. Perjamuan Kudus bukanlah sebagai alat keselamatan, tetapi manfaatnya hanyalah menguatkan iman saja. ${ }^{6}$

Jadi Ulrich Zwingli menyimpulkan bahwa Perjamuan Kudus hanya memperingati sebagai pengorbanan Yesus semata. Perjamuan Kudus tidak membawa Yesus kepada orang percaya tetapi Perjamuan Kudus membawa orang percaya mendekat kepada Yesus Kristus melalui iman. ${ }^{7}$ Sedangkan menurut pandangan Protestan, Yesus sungguh-sungguh hadir dalam Perjamuan Kudus tetapi tidak secara jasmaniah, melainkan secara rohani atau dinamis. Pendapat Calvin mengatakan bahwa yang hadir hanyalah pengaruh dari Kristus

${ }^{2}$ Ibid., 160.

${ }^{3}$ Brake, Diktat Eklesiologi dan Eskatologi (Makassar: STT Jaffray, 2017), 72. Belum dipublikasikan

${ }^{4}$ Ibid.

${ }^{5}$ J. L. Ch. Abineno, Perjamuan Malam (Jakarta: BPK. Gunung Mulia, 1990), 61.

${ }^{6}$ Ibid., 62.

${ }^{7}$ Brake, Diktat Eklesiologi dan Eskatologi (Makassar: STT Jaffray, 2017), 72. Belum dipublikasikan. ${ }^{8}$ Millard J. Erickson, Teologi Kristen Volume Tiga (Malang: Gandum Mas, 2004), 413. 
saja. Sebagai contoh matahari tetap berada di langit, namun panas dan terangnya sampai ke bumi. Begitu jugalah radiasi Roh yang menyampaikan kepada kita suatu persatuan dari daging dan darah Kristus, (Yohanes Calvin, Institutes fo the Christian Religion, book 4, Chapter 17, section 12). ${ }^{8}$

Menurut Liturgi Perjamuan Kudus Huria Kristen Batak Protestan 1951 Pasal 10 B yang menyatakan bahwa: Kita percaya dan menyaksikan Perjamuan Kudus ialah memakan roti, dengan roti mana (parhitean) kita terima daging dari Yesus Kristus Tuhan kita dan minum anggur, dengan anggur mana kita terima darah Tuhan kita Yesus Kristus, supaya kita peroleh keampunan dosa, hidup dan sejahtera (Korintus 11:17-34, Matius. 26, Markus. 14, Lukas 22). ${ }^{8}$ Menurut pandangan gereja Tiberias Indonesia, bahwa roti dan anggur dalam Perjamuan Kudus adalah benar-benar tubuh dan darah Kristus. Atas dasar ajaran Tuhan bahwa hanya seorang martir (saksi Allah) yang dapat berkata: Inilah tubuh Yesus, inilah darah Yesus. Tuhan Yesus mengajarkan langsung sakramen Perjamuan Kudus kepada Pdt. Yesaya Pariadji untuk membentuk roti menjadi tubuh Yesus Kristus dan anggur menjadi darah Yesus Kristus. ${ }^{9}$

\section{Pokok Masalah}

Berdasarkan latar belakang yang telah diuraikan di atas, maka yang menjadi pokok permasalahan dalam penulisan skripsi ini adalah:

Pertama, Apa makna roti dan anggur dalam Perjamuan Kudus berdasarkan Injil Matius 26:26-29?

Kedua, Apa implikasinya terhadap pengajaran Perjamuan Kudus dalam Gereja?

\section{Tujuan Penelitian}

Sesuai dengan masalah yang muncul diatas, maka tujuan penulisan skripsi ini adalah

Pertama, memaparkan kajian biblika mengenai makna roti dan anggur dalam Perjamuan Kudus berdasarkan Matius 26:26-29. Gereja.

Kedua, menjelaskan dan implikasi terhadap pengajaran Perjamuan Kudus dalam

\section{Manfaat Penelitian}

Penulisan akan skripsi ini diharapkan dapat memberikan manfaat bagi para pembaca skripsi ini, adapun manfaat yang dapat diperoleh dari penulisan skripsi ini adalah:

Pertama, agar skripsi ini dapat menjadi bahan bacaan bagi para pembacanya.

Kedua, agar dapat menjadi acuan atau dasar Alkitabiah mengenai makna roti dan anggur dalam Perjamuan Kudus.

Ketiga, untuk memenuhi salah satu persyaratan dalam menyelesaikan studi pada Sekolah Tinggi Filsafat Jaffray Makassar.

Keempat, agar dapat dijadikan bahan tambahan bacaan di Perpustakaan Sekolah Tinggi Filsafat Jaffray Makassar.

\footnotetext{
${ }^{8}$ Binsar Jonathan Pakpahan, "Analisis Kristen Liturgi Perjamuan Kudus Huria Batak Protestan," Indonesian Journal of Theology 2, No. 1 (July 2014):42-64, diakses 12 Agustus 2019.

${ }_{9}$ Yesaya Pariadji, Saya Digandeng Tuhan Yesus Ke Sorga (Jakarta: PT. Cherubim Production Indonesia, 2015), 135.
} 


\section{Metode Penelitian}

Metode penelitian yang digunakan oleh penulis dalam menulis skripsi ini adalah metode kualitatif, ${ }^{10}$ terhadap berbagai sumber diantaranya: Alkitab, buku-buku tafsiran yang membahas tentang roti dan anggur dalam Perjamuan Kudus dan juga ditunjang dengan bantuan media elektronik.

\section{Batasan Penelitian}

Untuk batasan akan penulisan skripsi ini, penulis hanya akan membahas mengenai kajian biblika mengenai makna roti dan anggur dalam Perjamuan Kudus berdasarkan Matius 26:26-29. Penulis akan mengambil kutipan-kutipan dari ayat-ayat Alkitab dan buku-buku lain sebagai referensi untuk menunjang penulisan skripsi ini. Penelitian yang relevan dengan perjamuan kudus ditampilkan dalam tulisan ini. ${ }^{11}$

\section{Sistematika Penulisan}

Penulisan skripsi ini menggunakan sistematika penulisan sebagai berikut:

Bab satu, pendahuluan: latar belakang masalah, pokok masalah, tujuan penelitian, manfaat penelitian, metode penelitian, batasan penelitian dan sistematika penulisan.

Bab dua, tinjauan pustaka: gambaran umum Injil Matius, penulis dan tanggal penulisan Injil Matius, tujuan Injil Matius, penerima Injil Matius, tema-tema Injil Matius, garis-garis besar Injil Matius, ciri-ciri khas Injil Matius.

Bab tiga, eksegesis, genre nas, analisis struktur, analisis konteks, analisis konteks sebelum, analisis konteks sesudah, analisis teks, analisis historis, analisis sastra.

Bab empat, implikasi.

Bab lima, kesimpulan, dan saran-saran.

\section{Kesimpulan}

Berdasarkan hasil uraian penulis dalam skripsi ini, maka penulis menarik dua kesimpulan mengenai makna roti dan anggur dalam Perjamuan Kudus berdasarkan Matius 26:26-29 dan implikasinya terhadap pengajaran Perjamuan Kudus dalam gereja, kesimpulan yang penulis dapat berikan adalah sebagai berikut:

\footnotetext{
${ }^{10}$ Helaluddin and Hengki Wijaya, Analisis Data Kualitatif Sebuah Tinjauan Teori \& Praktik (Makassar: Sekolah Tinggi Theologia Jaffray Makassar, 2019); Hengki Wijaya, Metodologi Penelitian Pendidikan Teologi (Makassar: Sekolah Tinggi Theologia Jaffray Makassar, 2016).

${ }^{11}$ Hanny Frederik, "Konsep Persatuan Dengan Kematian Dan Kebangkitan Kristus Berdasarkan Roma 6:1-14,” Jurnal Jaffray 13, no. 2 (September 29, 2015): 215-48, https://doi.org/10.25278/jj71.v13i2.179; Steven L. Ware, "Cracking The Code Of Easter Or, Understanding Why The Date Of Easter 'Hops' All Over The Calendars Of March And April," Jurnal Jaffray 13, no. 2 (June 24, 2015): 167-84, https://doi.org/10.25278/jj71.v13i2.176; Nicolas Rande and Daniel Ronda, "Makna Kebangkitan Kristus Berdasarkan I Korintus 15:12-28 Dan Implikasinya Bagi Orang Percaya,” Jurnal Jaffray 11, no. 2 (October 2, 2013): 1-28, https://doi.org/10.25278/jj71.v11i2.79; Hengki Wijaya, "Pengenaan Manusia Baru Di Dalam Kristus: Natur, Proses, Dan Fakta Serta Implikasi Teologis Dan Praktisnya," Jurnal Jaffray 14, no. 1 (March 22, 2016): 109, https://doi.org/10.25278/jj71.v14i1.194; Aldorio Flavius Lele and Robi Panggarra, "Makna Tujuh Ungkapan Yesus Di Salib Bagi Orang Percaya," Jurnal Jaffray 13, no. 2 (September 29, 2015): 285-316, https://doi.org/10.25278/jj71.v13i2.181.
} 
Pertama, Makna roti dalam Perjamuan Kudus sebagai lambang dari tubuh-Nya yang akan dipecah-pecahkan untuk diberikan kepada murid-murid-Nya. Roti yang dilambangkan sebagai tubuh-Nya mengarah kepada kematian-Nya, bahwa tubuh-Nya akan mati dan hal tersebut sebagai tanda Ia akan menyerahkan tubuh-Nya kepada kematian.

Kedua, Makna cawan dalam Perjamuan Kudus adalah sebagai simbol dari darah Yesus yang akan ditumpahkan, dicurahkan untuk pengampunan dosa semua orang. Darah Yesus adalah darah perjanjian baru menggantikan darah perjanjian lama dalam Perjanjian Lama (Kel.24:8). Darah perjanjian baru berfungsi sebagai pendamai antara Allah dengan manusia, memulihkan kembali hubungan Allah dengan umat-Nya, dan ini merupakan ketetapan dari Allah sendiri.

\section{Saran-Saran}

Adapun saran yang dapat penulis berikan berdasarkan seluruh uraian dalam penulisan skripsi ini adalah sebagai berikut:

Pertama, penulis berharap agar skripsi ini menjadi acuan untuk menyoroti Perjamuan Kudus sebagai suatu kesembuhan Ilahi. Karena sangat penting untuk memahami roti dan anggur dalam Perjamuan Kudus hanya sebagai lambang dari tubuh dan darah Yesus Kristus. Dengan demikian penulis sangat mengharapkan juga kepada para pembaca skripsi ini, agar menjadikannya sebagai pedoman untuk mengkaji dan menganalisis lebih lanjut makna roti dan anggur dalam Perjamuan Kudus bagi siapa saja yang ingin mengkajinya lagi.

Kedua, gereja harus selalu mengadakan Perjamuan Kudus, mengingat Perjamuan Kudus adalah perintah Tuhan untuk dilakukan sebagai suatu peringatan dan memberitakan kematian Tuhan sampai Ia datang (1 Korintus 11:25-26). Jadi sampai kapan Perjamuan Kudus dilakukan? Tuhan mengatakan bahwa sampai Ia datang kembali menjemput orangorang kudus-Nya, untuk bersama-sama masuk ke dalam Kerajaan-Nya yang kekal kelak.

Ketiga, hamba Tuhan harus mendorong jemaat untuk ikut mengambil bagian dalam Perjamuan Kudus, maka jemaat akan semakin mengenal bahwa betapa besar kasih Tuhan bagi kita yang rela memberikan darah dan nyawa-Nya menjadi tebusan bagi semua orang, dan hanya melalui darah-Nya, dosa dapat dihapus dan setiap pelanggaran diampuniNya.

Keempat, sebagai orang percaya tentunya berharap agar semua orang dapat diselamatkan, oleh sebab itu yang menjadi tugas dan tanggungjawab orang percaya adalah memberitakan Kristus sebagai Jurus'lamat. Agar semua orang dapat turut ikut dalam mengambil bagian dalam Sakramen Perjamuan Kudus. 


\section{Kepustakaan}

Alkitab Elektronik : Sabda (OLB versi Indonesia), Version: 14. 13. 02, Nov. 29, 2011, 09. 41.

Abineno, J. L. Ch. Perjamuan Malam. Jakarta: BPK. Gunung Mulia, 1990.

Barclay, William. Pemahaman Alkitab Setiap Hari, Matius pasal 1-10. Jakarta: BPK. Gunung Mulia, 1991.

. Pemahaman Alkitab Setiap Hari, Injil Matius Pasal 11-28. Jakarta: BPK. Gunung Mulia, 2015.

Becker, Theol. Dieter. Pedoman Dogmatika, Suatu Kompendium Singkat. Jakarta: BPK. Gunung Mulia, 1991.

Benyamin, Samuel. Perjanjian Baru, Sejarah, Pengantar dan Pokok-pokok Teologisnya. Bandung: Bina Media Informasi, 2010.

Bergant Dianne, \& Robert J. Karris. Tafsir Alkitab Perjanjian Baru. Yogyakarta: Kanisius, 2002.

Brake, Andrew. Diktat Eklesiologi dan Eskatologi. Makassar: Sekolah Tinggi Filsafat Jaffray, 2017. Belum dipublikasikan.

Brown, Jeannine K. Matthew. United States of America: Baker Books, 2015.

Bruce, F. F. Ucapan Yesus Yang Sulit. Malang: Literatur SAAT, 1995.

Bruggen, Jakob van. Kristus di Bumi. Jakarta: BPK. Gunung Mulia, 2004.

Chapman, Adina. Pengantar Perjanjian Baru. Bandung: Kalam Hidup, 2014.

Clark, Dennis E. Yesus Sang Mesias, Kehidupan dan Ajaran. Surabaya: Yakin, 1977.

Douglas, J. D. Ensiklopedi Alkitab Masa Kini. Jakarta: Yayasan Komunikasi Bina Kasih, Jilid 1, 1982.

Erickson, Millard J. Teologi Kristen Volume Tiga. Malang: Gandum Mas, 2004.

Fee, Gordon D., dan Douglas Stuart. Hermeneutik Bagaimana Menafsirkan Firman Tuhan dengan Tepat. Malang: Gandum Mas, 1989.

France, R. T. Matthew, Tyndale New Testament Commentaries. England: Wm. B. Eerdmans Publishing, 1999.

Frederik, Hanny. "Konsep Persatuan Dengan Kematian Dan Kebangkitan Kristus

Berdasarkan Roma 6:1-14.” Jurnal Jaffray 13, no. 2 (September 29, 2015): 215-48. https://doi.org/10.25278/jj71.v13i2.179.

Gering, Howard M. Analisa Alkitab. Jakarta: Immanuel, 1992.

Guthrie, Donald. Pengantar Perjanjian Baru Volume 1. Surabaya: Momentum, 2010.

Hadiwijono, Harun. Iman Kristen. Jakarta: BPK Gunung Mulia, 2005.

Hagner, Donald A. Matthew 14-28, Volume 33B. Zondervan Academic, 2018.

Halley, Henry H. Penuntun ke Dalam Perjanjian Baru. Surabaya: Yakin, 1979.

Heer, J. J. "Tafsiran Alkitab: Injil Matius 1 - 22: J.J. de Heer - Belbuk.com.” diakses 25

Maret 2019. https://www.belbuk.com/tafsiran-alkitab-injil-matius-1-22-p-12548. html.

Helaluddin, and Hengki Wijaya. Analisis Data Kualitatif Sebuah Tinjauan Teori \& Praktik. Makassar: Sekolah Tinggi Theologia Jaffray Makassar, 2019.

Hendry, Matthew. Injil Matius. Surabaya: Momentum, 2008.

Jonch, Christian. Metode Praktis Penyelidikan Alkitab. Jakarta: BPK. Gunung Mulia, 2017. 
Kee, Howard Clark, David G Burke, dan Steven W. Berneking. Alkitab Edisi studi. Jakarta: Lembaga Alkitab Indonesia, 2010.

Legg, Jhon. The King and His Kingdom, Matthew Simply Explained. England: Evangelical Press, 2014.

Lele, Aldorio Flavius, and Robi Panggarra. "Makna Tujuh Ungkapan Yesus Di Salib Bagi

Orang Percaya.” Jurnal Jaffray 13, no. 2 (September 29, 2015): 285-316.

https://doi.org/10.25278/jj71.v13i2.181.

Moore, David H., dan Yakob Tomatala. Dasar-Dasar Penyelidikan Alkitab. Jakarta: YT. Leadership Foundation, 1998.

Morris, Leon. Injil Matius. Surabaya: Momentum, 2016.

Mounce, Robert H. Matthew, Understanding The Bible Commentary Series. USA: Baker Books, 2011.

Nielsen, J. T. Tafsiran Alkitab, Kitab Injil Matius 23-28. Jakarta: BPK. Gunung Mulia, 2009.

Niftrik, Gerrit Cornelis van, dan B Boland J. Dogmatika Masa Kini. Jakarta: BPK Gunung Mulia, 2006.

Pakpahan, Binsar Jonathan. “Analisis Kritis Liturgi Perjamuan Kudus Huria Kristen Batak Protestan," Indonesian Journal of Theology 2, No. 1 (July 2014): diakses 12 Agustus 2019.

Packer, J. L., Merril C. Tenney, dan William White. Ensiklopedi Fakta Alkitab. Malang: Gandum Mas, 2001.

Pfeiffer, Charles F., dan Everett F Harrison. Tafsiran Alkitab Wycliffe, Volume 3 Perjanjian Baru. Malang: Gandum Mas, 2013.

Ponto, Rudolof Sripaus. "Kajian Biblika Tentang Kasih yang Semula berdasarkan Wahyu 2:1-7 dan Implikasinya bagi Orang Percaya Masa Kini.” (Skripsi S.Th, STTJ, Makassar, 2015).

Rande, Nicolas, and Daniel Ronda. "Makna Kebangkitan Kristus Berdasarkan I Korintus 15:12-28 Dan Implikasinya Bagi Orang Percaya.” Jurnal Jaffray 11, no. 2 (October 2, 2013): 1-28. https://doi.org/10.25278/jj71.v11i2.79.

Rumahlatu, Jerry. Hermeneutika Sepanjang Masa. Jakarta: Cipta Varia Sarana, 2011.

Santoso, David Imam. Teologi Matius. Malang: Literatur SAAT, 2009.

Scheunemann, Rainer. Panduan Lengkap Penafsiran Alkitab, Perjanjian Lama \&

Perjanjian Baru. Yogyakarta: ANDI, 2013.

Solihin, Benny. 7 Langkah Menyusun Khotbah yang Mengubah Kehidupan. Malang:

Literatur SAAT, 2010.

Sosipater, Karel. Etika Perjanjian Baru. Jakarta: Suara Harapan Bangsa, 2010.

Stamps, Donald C. Alkitab Penuntun Hidup Berkelimpahan. Malang: Gandum Mas dan Lembaga Alkitab Indonesia, 1994.

Stanley, David M. Tafsir Perjanjian Baru 1, Injil Matius. Yogyakarta: Yayasan Kanisius, 1981.

Suharyo, I. Pengantar Injil Sinoptik. Malang: Literatur SAAT, 2009.

Sutanto, Hasan. Hermeneutik: Prinsip dan Metode Penafsiran Alkitab. Edisi Revisi. Malang: Literatur SAAT, 2015.

. Perjanjian Baru Interlinear Yunani-Indonesia dan Konkordansi Perjanjian Baru

Jilid I. Edisi Revisi. Jakarta: Lembaga Alkitab Indonesia, 2014. 
. Perjanjian Baru Interlinear Yunani-Indonesia dan Konkordansi Perjanjian Baru Jilid II. Edisi Revisi. Jakarta: Lembaga Alkitab Indonesia, 2014.

Sykes, R. H. Matthew, Presenting-Jesus the King. Canada: Everyday Publications, 1984.

Tenney, Merrill. "Pengantar Perjanjian Baru | Ical Pangalerang - Academia.edu." diakses 18 Maret 2019. https://www.academia.edu/12660071/Pengantar_Perjanjian_Baru.

Vanhoozer, Kevin J. Drama Doktrin, Suatu Pendekatan Kanonik-Linguistik pada Theologi Kristen. Surabaya: Momentum, 2011.

Ware, Steven L. "Cracking The Code Of Easter Or, Understanding Why The Date Of Easter 'Hops' All Over The Calendars Of March And April.” Jurnal Jaffray 13, no. 2 (June 24, 2015): 167-84. https://doi.org/10.25278/jj71.v13i2.176.

Wiersbe, Warren W. Loyal Di Dalam Kristus. Bandung: Kalam Hidup, 2012.

Wijaya, Hengki. Metodologi Penelitian Pendidikan Teologi. Makassar: Sekolah Tinggi Theologia Jaffray Makassar, 2016.

. "Pengenaan Manusia Baru Di Dalam Kristus: Natur, Proses, Dan Fakta Serta Implikasi Teologis Dan Praktisnya.” Jurnal Jaffray 14, no. 1 (March 22, 2016): 109. https://doi.org/10.25278/jj71.v14i1.194.

Wongso, Peter. Hikayat Yesus, Penguraian dan Penafsiran Kehidupan Yesus dalam Empat Kitab Injil. Malang: Literatur SAAT, 1998. 